\title{
Plant-driven variation in decomposition rates improves projections of global litter stock distribution
}

\author{
V. Brovkin ${ }^{1}$, P. M. van Bodegom ${ }^{2}$, T. Kleinen ${ }^{1}$, C. Wirth ${ }^{3}$, W. K. Cornwell ${ }^{4}$, J. H. C. Cornelissen ${ }^{2}$, and J. Kattge \\ ${ }^{1}$ Max Planck Institute for Meteorology, Bundesstr. 53, 20146, Hamburg, Germany \\ ${ }^{2}$ Systems Ecology, Institute of Ecological Science, Faculty of Earth and Life Sciences, VU University, The Netherlands \\ ${ }^{3}$ Institute of Biology, University of Leipzig, Germany \\ ${ }^{4}$ Department of Integrative Biology, University of California, Berkeley, USA \\ ${ }^{5}$ Max-Planck-Institute for Biogeochemistry, Jena, Germany \\ Correspondence to: V. Brovkin (victor.brovkin@zmaw.de)
}

Received: 19 July 2011 - Published in Biogeosciences Discuss.: 29 August 2011

Revised: 26 December 2011 - Accepted: 14 January 2012 - Published: 30 January 2012

\begin{abstract}
Plant litter stocks are critical, regionally for their role in fueling fire regimes and controlling soil fertility, and globally through their feedback to atmospheric $\mathrm{CO}_{2}$ and climate. Here we employ two global databases linking plant functional types to decomposition rates of wood and leaf litter (Cornwell et al., 2008; Weedon et al., 2009) to improve future projections of climate and carbon cycle using an intermediate complexity Earth System model. Implementing separate wood and leaf litter decomposabilities and their temperature sensitivities for a range of plant functional types yielded a more realistic distribution of litter stocks in all present biomes with the exception of boreal forests and projects a strong increase in global litter stocks by $35 \mathrm{GtC}$ and a concomitant small decrease in atmospheric $\mathrm{CO}_{2}$ by 3 ppm by the end of this century. Despite a relatively strong increase in litter stocks, the modified parameterization results in less elevated wildfire emissions because of a litter redistribution towards more humid regions.
\end{abstract}

\section{Introduction}

Extensive ground-based measurements of plant biochemistry, physiology, and ecology have led to a much better quantification of ecosystem processes during the last decades (Hassan et al., 2005). Recent assimilation of many thousands of measurements of species traits in global databases (Wright et al., 2004; Kattge, 2011a) opens a new perspective to specify plant parameters used in ecosystem models which predominantly operate at the level of large-scale plant units such as plant functional types (PFTs) (Cramer et al., 2001).
Instead of constraining model parameters using values from a few publications, a novel approach aggregates plant traits from the species level to the PFT level using trait databases (Kattge et al., 2009).

Models of the terrestrial carbon cycle are composed of a part related to the functioning of living plants and a part describing the decomposition of plant litter and soil organic matter. While the former processes are quantified relatively well (Denman et al., 2007), the decomposition processes are much less constrained by observations, essentially because of the long time scales involved and the limited applicability of remote sensing data. In particular, litter decomposition is poorly quantified in ecosystem models used at a global scale (Cornwell et al., 2009) although it is an important integrative part of the carbon cycle. Besides, litter serves as a fire fuel and is therefore a central part of the fire disturbance process which drives ecosystem changes. Moreover, decomposition, especially of leaf litter, is a key component of nutrient (nitrogen, $\mathrm{N}$, and phosphorus, P) cycling in ecosystems. The nutrient feedback of litter and soil decomposition to plant productivity has long been neglected in most Earth System models used for future carbon cycle projections (Denman et al., 2007), although there are recent advances both for $\mathrm{N}$ (Churkina et al., 2009; Gerber et al., 2010; Sokolov et al., 2008; Thornton et al., 2007; Zaehle et al., 2010) and P cycling (Wang et al., 2010). The litter decomposition is driven not only by the nutrient content of the litter, but also by other chemical components such as lignin (Parton et al., 1993), and accounting for litter quality is an essential further step in the global vegetation models. 
Here, we demonstrate the critical consequences of accounting for PFT-specific variation in litter decomposition parameters, compiled in global trait databases, upon litter stocks and fire disturbance using the Lund-Potsdam-Jena (LPJ) dynamic global vegetation model (DGVM) (Gerten et al., 2004; Sitch et al., 2003), complemented by a diagnostic representation of $\mathrm{N}$ and $\mathrm{P}$ stocks.

\section{Methods}

In the Sects. 2.1 and 2.2, we present methodology of obtaining litter decomposition rates from the global trait databases. In Sect. 2.3, we present the modelling tool, CLIMBER2-LPJ, a way of implementing the information from trait databases, and a setup of numerical experiments with this model.

\section{$2.1 \quad$ PFT-dependent leaf litter decomposition}

Leaf litter decomposition is commonly quantified either by direct field incubations or through "common garden" experiments. The latter procedure, in which litter samples of multiple species are all incubated simultaneously outdoors in a rather natural litter matrix, has as advantage that the decomposability of different species can be compared directly without confounding factors like differential access by detritivores or differences in microhabitat. Relative differences in decomposition rate of leaf litter, $k_{\text {leaf }}$, can thus be estimated in a robust, unbiased manner. A disadvantage of the use of common gardens experiments is that the absolute $k_{\text {leaf }}$ may slightly deviate from $k_{\text {leaf }}$ at field conditions. Therefore, we applied an approach combining the advantages of both methods: we compiled common garden experiments (Cornwell et al., 2008) that had incubated $\geq 6$ species (and $>20$ species in a subset of 14 studies) simultaneously to quantify the effects of litter quality on decomposability. The duration of the incubation varied from 30 to 1700 days. In a second step, we used litter with known litter quality and unbiased $k_{\text {leaf }}$ at reference conditions to scale $k_{\text {leaf }}$ for each litter quality to a true unbiased estimate of $k_{\text {leaf }}$ at reference conditions.

We applied litter lignin (lig, in \%) and nitrogen contents $(\mathrm{N}$, in $\%)$ as measures of litter quality, based on their strong correlations with decay rates (Parton et al., 2007). While the protocols for lignin analysis varied in their details across the studies from which data had been compiled, they generally used a version of the "van Soest" method (Allen, 1989) which involves sequential acid-detergent digestion steps leaving lignin as the recalcitrant residue (often with a separate correction for silica content through ashing in a furnace). We statistically tested the influence of lignin and nitrogen contents on litter decomposition rates, using the 542 species from 33 experiments on five continents for which both lignin contents and nitrogen contents were available in our ART-DECO dataset (Cornwell et al., 2008). This meta-analysis showed that both lignin and litter nitrogen were highly significantly related to $k_{\text {leaf }}(P<0.001$; analysis based on a general linear model with lignin and nitrogen, while using site as a random factor). $F$-values were 55.7 and 116.2 for nitrogen and lignin, respectively. The effects of the litter traits on litter $k_{\text {leaf }}$ were thus strong and standard errors of the regression coefficients were small ( 0.045 for log-lignin and 0.056 for $\log \mathrm{N}$, respectively).

Subsequently, we used litter with known litter quality that had been incubated at the reference conditions ("reference litter") to scale $k_{\text {leaf }}$-values to true unbiased field level decomposition rates $k_{\text {leaf }}$ at reference conditions; $k_{\text {leaf } 10}$. For this reference litter, we took data from those sites in our database that had a mean annual temperature (mat) between 8 and $12{ }^{\circ} \mathrm{C}$, which had not been obviously constrained by low precipitation and in which incubation conditions strongly resembled that of litter in situ. These studies included temperate rainforest in New Zealand, temperate forest in Poland and temperate peatland and woodlands in The Netherlands. The Grand Mean of leaf litter $k_{\text {leaf } 10}$ across these studies, after accounting for the dependence on lignin and nitrogen as described above and measured for the reference litter, was taken to represent reference litter decomposition at mat of $10{ }^{\circ} \mathrm{C}$.

Finally, we combined both steps of our analysis into Eq. (1) to estimate $k_{\text {leaf10 }}^{\mathrm{pft}}$, the PFT-dependent decomposition rates of leaf litter at a reference temperature of $10^{\circ} \mathrm{C}$ :

${ }^{10} \log k_{\text {leaf } 10}^{\mathrm{pft}}={ }^{10} \log k_{\text {leaf } 10}^{\text {ref }} \frac{a \cdot{ }^{10} \log \left(\mathrm{lig}^{\mathrm{pft}}\right)+b \cdot{ }^{10} \log \left(\mathrm{N}^{\mathrm{pft}}\right)}{a \cdot{ }^{10} \log \left(\mathrm{lig}^{\mathrm{ref}}\right)+b \cdot{ }^{10} \log \left(\mathrm{N}^{\mathrm{ref}}\right)}$

Parameters $a=-0.350$ and $b=0.417$ refer to the regression coefficients, as analysed above, identifying the impacts of lignin and litter nitrogen on $k_{\text {leaf }}$. Index ref refers to the reference litter and lig ${ }^{\text {ref }}$ and $\mathrm{N}^{\text {ref }}$ are arithmetic means across reference litters in the ART-DECO database. To apply Eq. (1) in this study, we derived ligpft and $\mathrm{N}^{\mathrm{pft}}$ as arithmetic means of litter chemistry per PFT in the ART-DECO database (Table 1). The assignment of species to PFTs was based on botanical information on leaf habit, life-form and the biome of origin according to the definitions in LPJ. The resultant $k_{\text {leaf10 }}^{\mathrm{pft}}$ values (as applied in Sect. 2.3) are provided in Table 1.

To cross-validate our $k_{\text {leaf }}$ estimates, we calculated $k_{\text {leaf }}$ at the environmental conditions prevailing during the respective incubations, using the LPJ formulation of leaf decomposition dependence on temperature and moisture (see Sect. 2.3 and Fig. 1). The $k_{\text {leaf }}$ values predicted this way explained $75 \%$ of the variance in observed litter $k_{\text {leaf }}$ values with remaining variance tentatively explained by non-accounted leaf chemical compounds such as tannins and soil macro-detritivores (Hattenschwiler and Jorgensen, 2010). Although our leaf litter database also included tannin contents, we did not include tannins in Eq. (1) for three reasons: (1) tannins were less well covered in our database, (2) the relation between tannins and $k_{\text {leaf }}$ (in particular, important in some tropical studies) was generally weaker than the relation between lignin and $k_{\text {leaf }}$, 
Table 1. Litter decomposition parameters, $k$, at $10^{\circ} \mathrm{C}$ and litter temperature sensitivities $\left(Q_{10}\right)$ used in the WKQ simulation. ${ }^{*}$

\begin{tabular}{|c|c|c|c|c|c|}
\hline \multirow[t]{2}{*}{$\begin{array}{l}\text { LPJ plant } \\
\text { functional type }\end{array}$} & \multicolumn{2}{|c|}{$\begin{array}{l}\text { Leaf litter concentration, } \\
\qquad \%\end{array}$} & \multirow[t]{2}{*}{$\begin{array}{l}k_{\text {leaft }}^{\mathrm{pft}}, \\
\mathrm{yr}^{-1}\end{array}$} & \multirow[t]{2}{*}{$\begin{array}{l}k_{\text {wood } 10}^{\mathrm{pft}} \\
\mathrm{yr}^{-1}\end{array}$} & \multirow[t]{2}{*}{$\begin{array}{l}\text { Woody litter } \\
Q_{10}{ }^{* *}\end{array}$} \\
\hline & ligpft & $\mathrm{N}^{\mathrm{pft}}$ & & & \\
\hline Tropical broadleaved evergreen trees (TrBE) & $17.8 \pm 0.5$ & $0.95 \pm 0.03$ & 0.93 & 0.039 & 2.75 \\
\hline Tropical broadleaved raingreen trees (TrBR) & $14.5 \pm 1.3$ & $1.63 \pm 0.13$ & 1.17 & 0.039 & 2.75 \\
\hline Temperate needleleaved evergreen trees (TeNE) & $24.4 \pm 1.0$ & $0.73 \pm 0.06$ & 0.70 & 0.041 & 1.97 \\
\hline Temperate broadleaved evergreen trees (TeBE) & $21.0 \pm 0.7$ & $0.86 \pm 0.03$ & 0.86 & 0.104 & 1.37 \\
\hline Temperate broadleaved summergreen trees (TeBS) & $16.9 \pm 1.3$ & $1.02 \pm 0.04$ & 0.95 & 0.104 & 1.37 \\
\hline Boreal needleleaved trees $(\mathrm{BoN})$ & $25.6 \pm 4.1$ & $0.96 \pm 0.18$ & 0.76 & 0.041 & 1.97 \\
\hline Boreal broadleaved summergreen trees (BoBS) & $22.3 \pm 1.6$ & $0.89 \pm 0.06$ & 0.94 & 0.104 & 1.37 \\
\hline $\mathrm{C}_{3}$ grass $(\mathrm{H} \mathrm{C} 3)$ & $16.6 \pm 0.8$ & $1.37 \pm 0.07$ & 1.20 & - & - \\
\hline $\mathrm{C}_{4} \operatorname{grass}(\mathrm{H} \mathrm{C} 4)$ & $23.4 \pm 2.1$ & $0.97 \pm 0.11$ & 0.97 & - & - \\
\hline
\end{tabular}

* In the CTL simulation, decomposition rates for the leaf and woody litter at $10^{\circ} \mathrm{C}$ were set uniformly to $0.3 \mathrm{yr}^{-1}$. The sensitivity to temperature and soil moisture was defined following parameterizations by Lloyd and Taylor (1994) and Foley (1995), respectively. In the W simulation, $k_{\text {leaf } 10}$ and $k_{\text {wood } 10}$ equalled 0.94 and $0.057 \mathrm{yr}{ }^{-1}$, respectively, for all PFTs. ** $Q_{10}$ represents the relative increase in decomposition upon a $10^{\circ} \mathrm{C}$ temperature rise.

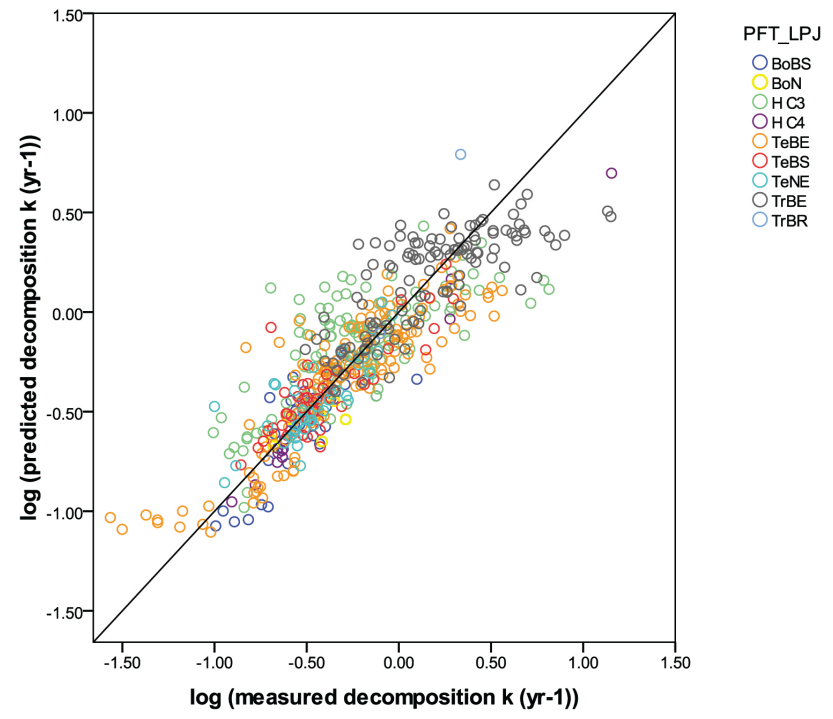

Fig. 1. Correspondence between measured $k_{\text {leaf }}(\mathrm{x}$-axis) versus predicted $k_{\text {leaf }}$ (y-axis) using Eq. (1) on a log-log scale. Predicted $k_{\text {leaf }}$ values are calculated using lignin and $\mathrm{N}$ concentrations accounting for decomposition dependence on temperature and soil moisture as parameterized in LPJ (Eqs. 4-6). Acronyms for LPJ woody PFTs are the same as in Table 1. The slope of predicted vs. measured values equals $1.00 \pm 0.025$.

and (3) lignin and $\mathrm{N}$ together have been most frequently used to predict global patterns in $k_{\text {leaf }}$ (e.g. Parton et al., 2007) and therefore using these parameters allows comparing our estimates with the those derived in previous studies.

\subsection{PFT-dependent woody litter decomposition rates}

PFT-dependent woody litter decomposition rates, $k_{\text {wood }}$, are based on the analysis of another trait database, Functional Ecology of Trees (FET), developed by the Organismic Biogeochemistry Group at the Max-Planck-Institute for Biogeochemistry in Jena (Weedon et al., 2009). FET contains 1511 data entries for values of $k_{\text {wood }}$ for 340 tree species from 66 plant families studied in 166 different locations across the world extracted from a total of 99 publications. Studies reporting wood decomposition rates and meeting the following criteria were considered: (1) decomposition rates were calculated using observations on loss of mass, carbon, or density, but not volume; (2) only values of $k_{\text {wood }}$ from a single-exponential decay model were used (i.e. no linear or lag-time models etc.); (3) the time axis was derived either from long-term observations or from chronosequences. Mass balance estimates based on woody detritus mass divided by input were excluded; (4) only whole organs including bark were studied (i.e. no wood chips etc.). This requirement was relaxed for tropical studies to include the comprehensive dataset from Usher and Ocloo (Usher and Ocloo, 1979) where wooden planks had been used; (5) only wood pieces exceeding a diameter of $1 \mathrm{~cm}$ were considered

Decomposition is an ecosystem-level process and depends on the activity of the decomposer community, which is controlled by abiotic factors (temperature, moisture, oxygen availability) and biotic factors (substrate quality and litter accessibility). To be able to account for these factors and to extract comparable decomposition rates $k_{\text {wood } 10}^{\mathrm{pft}}$ to be used in LPJ after aggregation to the PFT-level, information on important covariates was collected along with decomposition rates. Mean annual temperature, mat, and annual precipitation sum, ap, were included as climate data. Where available the values given in the publications were used. Otherwise data from 
Climatic Research Unit for years 1960-1999 (New et al., 1999) were used. The diameter of logs, $d$, was included as covariate controlling both accessibility and quality, the latter given that the fraction of chemically protected heartwood increases with size. The position of a tree, pos, influences the moisture content of the wood. Downed logs with soil contact exhibit greater moisture contents than standing snags. The assignment of PFTs was based on botanical information on leaf habit, life-form and the biome of origin according to the LPJ definitions (Sitch et al., 2003). The seven woody PFTs in LPJ were aggregated to evergreen broadleaved trees, deciduous broadleaved trees and needle-leaved trees. This was done to obtain more reliable estimates for the temperature sensitivity by increasing the temperature range covered by the data points per group.

The abovementioned information was used to derive the following general formulation of the statistical model:

$k_{\text {wood }}^{i}=k_{\text {wood } 10}^{\mathrm{pft}}\left(Q_{10}^{\mathrm{pft}}\right)^{\frac{T_{i}-10}{T_{\mathrm{ref}}}} \exp \left(\sum_{l} \beta_{l}^{\mathrm{pft}} c_{l}^{i}\right)+\varepsilon_{\mathrm{pft}}^{i}$,

where $i$ is a subscript for individual observation $(i=1, \ldots, n)$, pft is a subscript for the aggregated PFT $(1,2$, or 3$)$ for observation $i, l$ is a subscript for different covariates (ap, $d$, pos), $k_{\text {wood }}^{i}$ is the observed value of decomposition rate, $k_{\text {wood } 10}^{\mathrm{pft}}$ is the value of decomposition rate of woody litter of given PFT for the reference $10^{\circ} \mathrm{C}$ temperature $T_{\text {ref }}$ (see detailed definition below), $Q_{10}^{\mathrm{pft}}$ is the relative increase in $k_{\text {wood }}^{\mathrm{pft}}$ upon a temperature increase of $10^{\circ} \mathrm{C}$ for given PFT. $\varepsilon_{\mathrm{pft}}^{i}$ is the residual error component and $\beta_{l}^{\mathrm{pft}}$ are parameters of the statistical model. The three covariates $c_{l}^{i}$ used here are the annual precipitation sum ap (in $\mathrm{mm}$ ), the initial diameter $d$ (in $\mathrm{cm}$ ) and a binary position indicator, pos, that takes a value of 1 when elevated and 0 for soil contact. The continuous covariates ap and $d$ were $z$-transformed [(value-mean)/SD]. Temperature was not transformed in order to be compatible with the standard $Q_{10}$-formulation. The data matrix was filled with the exception of the initial diameter $d$ (with 119 missing values out or 1511) and the missing data were imputed within the estimation algorithm.

After log-transformation on both sides, Eq. (2) yields

$\underbrace{\ln k_{\mathrm{wood}}^{i}}_{k^{*}}=\underbrace{\ln k_{\mathrm{wood} 10}^{\mathrm{ptt}}}_{k^{\prime *}}+\underbrace{\ln Q_{10}^{\mathrm{pft}}}_{q^{*}} \times \frac{T_{i}-10}{T_{\mathrm{ref}}}+\sum_{l} \beta_{l}^{\mathrm{pft}} c_{l}^{i}+\underbrace{\ln \varepsilon_{\mathrm{pft}}^{i}}_{\varepsilon^{\prime}}$,

where $\varepsilon^{\prime}=N\left(\operatorname{pred}\left(\ln k_{\text {wood }}^{i}\right), \sigma_{\text {pft }}^{2}\right)$, i.e. the errors are normally distributed around the predicted log-transformed $k$ value with the estimated variance $\sigma_{\mathrm{pft}}^{2}$ for each PFT. Equation (3) was analyzed with WinBUGS (Lunn et al., 2000) using only non-informative ("flat") priors to avoid the introduction of prior information into the estimation. The resultant estimates of parameters $k^{*}$ and $q^{*}$ were back-transformed to their original units (see Table 1), which resulted in lognormal error distributions at the original scale. Comparison

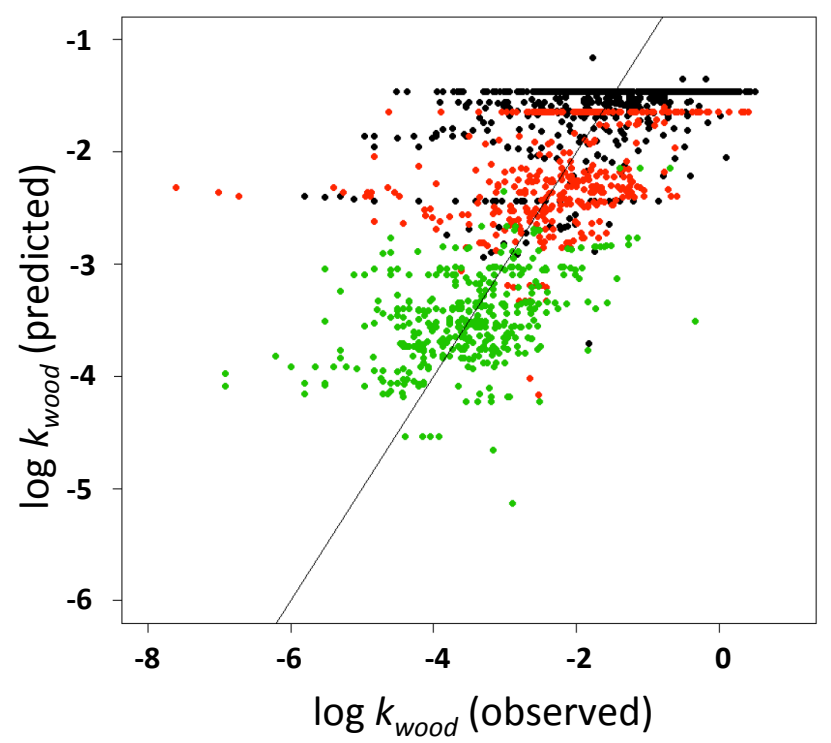

Fig. 2. Observed (x-axis) versus predicted (y-axis) decomposition rates of coarse woody debris at the log-scale. Green $=$ evergreen needleleaved (boreal and temperate), red circles $=$ deciduous broadleaved (boreal to tropical), black = evergreen broadleaved (mostly tropical). The model controls for effects of log size, precipitation, and soil contact. The large residual variation (and the low overall adjusted $R^{2}$ of 0.43 ) compared to litter decomposition is due to strong species-specific variation in decay preventing chemical constituents and decomposer communities. Observed values $(n=1409)$ are from the FET database (Weedon et al., 2009).

of observed versus predicted decomposition rates of coarse woody debris of the empirical model is shown in Fig. 2 and modelled sensitivity of coarse woody debris decomposition rates to mean annual temperature is presented in Fig. 3.

Two sets of PFT-specific parameters, $k_{\text {wood } 10}^{\mathrm{pft}}$ and $Q_{10}^{\mathrm{pft}}$, were used in LPJ. $k_{\mathrm{wood} 10}^{\mathrm{pft}}$ is the baseline decomposition rate for a given PFT under conditions (1) where the mean annual temperature $T\left({ }^{\circ} \mathrm{C}\right.$ ) is at a reference temperature $T_{\text {ref }}$ (set to $10^{\circ} \mathrm{C}$ ) and (2) where all covariates attain a value of zero. This refers to the mean values of ap $(1416 \mathrm{~mm}$, i.e. non limiting conditions) and $d(10.2 \mathrm{~cm})$ and the situation of a downed $\log$ in contact with the soil surface (pos $=0$ ). Sensitivities to covariates other than temperature, i.e. the $\beta_{l}^{\mathrm{pft}}$, were not used in LPJ. However, estimating them was necessary in order to extract comparable baseline rates.

\subsection{Setup of model experiments}

Similar to many DGVMs, the original formulation of the LPJ decomposition module (Sitch et al., 2003) did not consider separating litter into leaf and woody components. The decomposition rate, $k$, a reciprocal to the mean residence time of aboveground litter, was the same for all sources of litter (leaf, sapwood, and heartwood) and dependent on the soil temperature and moisture as follows: 


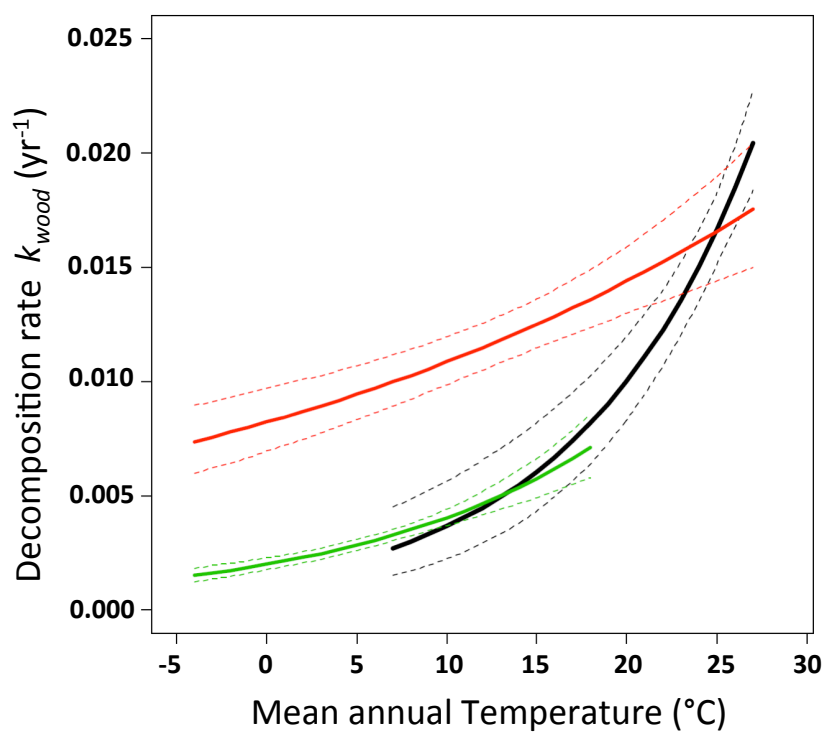

Fig. 3. Modelled sensitivity of coarse woody debris decomposition rates $\left(\mathrm{yr}^{-1}\right)$ to mean annual temperature (bold lines). The steepness of the curvature indicates differences in $Q_{10}$. The $95 \%$ confidence intervals (dash lines) are with respect to the mean predictions and do not contain the residual variation. Green = evergreen needleleaved, red $=$ deciduous broadleaved, black $=$ evergreen broadleaved.

$k=k_{10} g(T) f\left(S_{\mathrm{m}}\right)$,

where $k_{10}$ is decomposition rate for the reference temperature of $10^{\circ} \mathrm{C}$ and maximum soil moisture,

$g(T)=\exp \left[308.56 \cdot\left(\frac{1}{56.02}-\frac{1}{T+46.02}\right)\right]$

is a temperature dependence following Lloyd and Taylor (1994), and

$f\left(S_{\mathrm{m}}\right)=0.25+0.75 S_{\mathrm{m}}$

is a moisture dependence after Foley (1995). In Eqs. (46 ), the temperature $T$ is taken as the surface air temperature and $S_{\mathrm{m}}$ is the relative moisture of the upper soil layer in the model $(0-50 \mathrm{~cm})$. The $k_{10}$ value equalled $0.3 \mathrm{yr}^{-1}$ for both leaf and woody litter (Gerten et al., 2004).

Recent global compilations of ground-based observations of decomposition rates discussed in the Sect. 2.1-2.2 allowed for a new parameterization of litter decomposition for the nine PFTs used in LPJ. Firstly, the leaf and woody litter components were treated as separate pools and specified for each PFT. This is important because woody (especially coarse detritus) decomposition is slower by an order of magnitude than leaf decomposition. This step W (for woody and leaf litter separated) uses average $k_{\text {leaf } 10}$ and $k_{\text {wood10 }}$ values from the trait databases $\left(0.94\right.$ and $0.057 \mathrm{yr}^{-1}$ for the leaf and woody litter, respectively) to replace $k_{10}$. Secondly, $k_{\text {leaf10 }}^{\mathrm{pft}}$ and $k_{\text {wood10 }}^{\mathrm{pft}}$ were specified for each PFT based on data for their species representatives in litter databases for leaf litter (Table 1, see Sects. 2.1 and 2.2 above). This step is noted as $\mathrm{K}$ (for $k$ by PFT based on trait databases). In the third step Q (for $Q_{10}$ parameterization), dependence of woody litter decomposition on temperature was re-parameterized to account for PFT-dependent temperature sensitivity rates $\left(Q_{10}\right)$ using the FET dataset (Sect. 2.2) instead of the original LPJ parameterization where temperature dependence (Eq. 5) was the same for all PFTs (Lloyd and Taylor, 1994). We did not vary the $Q_{10}$ for leaf litter given that PFT variation in $Q_{10}$ for leaf litter seems small (Cornelissen et al., 2007) and given that the effect of different $Q_{10}$ values on the leaf litter storage is negligible in comparison with the $Q_{10}$ effect on woody litter storage. In all these three steps, the dependence of woody litter decomposition on soil moisture (Eq. 6) was not accounted for (see details in the Sect. 3).

Here we present results from four 2000-yr pre-industrial equilibrium LPJ simulations noted as CTL (original LPJ parameterization), W, WK, and WKQ (Table 4). The new PFTparameterizations were incorporated in LPJ (Gerten et al., 2004; Sitch et al., 2003), designed to represent land surface processes at a spatial resolution of $0.5^{\circ} \times 0.5^{\circ}$. The LPJ model simulates natural vegetation dynamics without accounting for the anthropogenic land cover changes. Four equilibrium simulations were performed to quantify effects of the new parameterizations step-by-step (Table 4).

The original formulation of LPJ has only one aboveground litter pool. However, the model calculates fluxes going into leaf and woody parts of the litter. Knowing these fluxes, we allocated them into separated leaf and woody litter storages and quantified these storages in the CTL simulation. Results of the diagnostic separation of woody litter storages are presented in Table 2 and discussed in the Sect. 3.

In addition, two transient runs were done by coupling LPJ to the intermediate complexity climate model CLIMBER-2 (Petoukhov et al., 2000) containing a oceanic biogeochemistry model (Brovkin et al., 2002). The atmospheric module of CLIMBER-2 operates at a coarse spatial resolution of $51^{\circ}$ in longitudinal and $10^{\circ}$ in latitudinal direction. Monthly climate anomalies from CLIMBER-2 are passed to LPJ, where they are added to climate patterns based on the Climatic Research Unit CRUTS climate data set (New et al., 2002). The carbon flux between atmosphere and land surface is determined from the annual change in the LPJ carbon pools, and employed in CLIMBER-2 to determine the $\mathrm{CO}_{2}$ concentration (Kleinen et al., 2010). In the transient simulations, CLIMBER2-LPJ was driven by historical $\mathrm{CO}_{2}$ emissions from 1751 to 2000 (Boden et al., 2010) and the SRES A2 scenario of fossil fuel and landuse emissions for the years 2001-2100 as in the C4MIP simulations (Friedlingstein et al., 2006) starting from pre-industrial equilibrium at the year 1750 (Table 4). 
Table 2. Summary of the Analysis of Variance (ANOVA) on the differences between woody litter stocks as represented in the FET dataset (noted as Data) and according to model simulations CTL and WKQ (presented in the box-and-whisker plots in Fig. 2). For the model outputs, only grid cells where the simulated fractional projection cover of the PFT in question was higher than $50 \%$ were taken into account.

\begin{tabular}{|c|c|c|c|c|c|c|c|c|c|c|c|}
\hline \multirow[t]{2}{*}{$\begin{array}{l}\text { LPJ } \\
\text { PFT }\end{array}$} & \multicolumn{3}{|c|}{$\begin{array}{c}n \text { (number of } \\
\text { sites or grid cells) }\end{array}$} & \multicolumn{3}{|c|}{$\begin{array}{l}\text { Mean litter stocks } \\
\mathrm{kg} \mathrm{C} \mathrm{m}^{-2}\end{array}$} & \multicolumn{3}{|c|}{$\begin{array}{r}\text { Standard deviation of } \\
\text { litter stocks, } \mathrm{kg} \mathrm{C} \mathrm{m}^{-2} \\
\end{array}$} & \multicolumn{2}{|c|}{$\begin{array}{l}F \text { value, } \\
\text { ANOVA }\end{array}$} \\
\hline & Data & CTL & WKQ & Data & CTL & WKQ & Data & CTL & WKQ & CTL & WKQ \\
\hline $\operatorname{TrBE}$ & 40 & 5443 & 5394 & 0.84 & 0.32 & 0.84 & 0.67 & 0.14 & 0.38 & 482.8 & 0.0 \\
\hline TrBR & 9 & 2430 & 2444 & 1.22 & 0.15 & 0.29 & 0.94 & 0.08 & 0.21 & 1080.0 & 178.2 \\
\hline TeNE & 100 & 1214 & 1238 & 6.47 & 0.61 & 2.40 & 6.86 & 0.31 & 1.30 & 873.9 & 298.9 \\
\hline TeBE & 13 & 822 & 679 & 6.26 & 0.39 & 0.94 & 6.74 & 0.20 & 0.43 & 637.1 & 370.2 \\
\hline TeBS & 53 & 448 & 434 & 1.75 & 0.60 & 1.25 & 2.39 & 0.24 & 0.44 & 97.0 & 11.5 \\
\hline $\mathrm{BoN}$ & 68 & 9049 & 9051 & 2.35 & 1.58 & 4.32 & 2.71 & 0.64 & 1.87 & 86.0 & 76.4 \\
\hline BoBS & 8 & 3662 & 3626 & 0.84 & 0.92 & 0.80 & 1.07 & 0.27 & 0.27 & 0.8 & 0.13 \\
\hline
\end{tabular}

* The ANOVA used quantifies the difference between two independent datasets: observed data from the FET dataset and results of either CTL or WKQ simulations. The difference between observed data and either model was always statistically significant at the $p<0.05$ level (except of the TrBE PFT for the WKQ simulation) due to the very high number of observations. Although the differences may be statistically different, they might not represent biologically relevant differences. Therefore, the $F$-values, representing the variance explained by differences among dataset over the residual variance, was used to compare model outputs. The $F$ values for the WKQ experiment were always lower than for the CTL experiment implying that the WKQ results were closer to the observed data than the CTL results.

\section{Results}

The original LPJ parameterization (CTL) results in the largest litter stocks in the boreal and tundra regions of the Northern Hemisphere (Fig. 4, top). The litter stocks in the polar tundra region are overestimated, in particular in northeastern Siberia, where observations (Bazilevich, 1993) report litter stocks of $0.3-1 \mathrm{~kg} \mathrm{C} \mathrm{m}^{-2}$ while the model simulates 4 to $8 \mathrm{~kg} \mathrm{C} \mathrm{m}^{-2}$. At the same time, comparison with observationbased estimates for woody litter stocks (Table 2) reveals that woody litter is underestimated in all other regions and increasingly so towards tropical regions (Fig. 5), in particular because of unrealistically high $k_{\text {wood }}$ values. This cumulates in a global litter amount of $184 \mathrm{GtC}$ which is beyond or at the upper range of estimates of litter stocks based on observations (68-97 Gt C) or models (47-196 Gt C) (Matthews, 1997), respectively. Accounting for the omission of anthropogenic deforestation in the model simulations, the total global CTL litter stock estimate is plausible, but ground observations demonstrate clearly that the original CTL parameterization shifts the litter stocks erroneously from forested temperate regions towards the tundra region.

In the WKQ simulation, the global total amount of litter $(191 \mathrm{GtC})$ is very similar to the results of the CTL simulation. However, the spatial patterns of litter distribution are distinct from the CTL simulation as the largest litter stocks are located in the boreal forest zone while the polar region has much less litter (Fig. 4, bottom). The litter stock in the tropical regions increases. When comparing to empirical woody litter stock data, the WKQ results are closer to the observations (Fig. 5). The model slightly underestimates the litter stocks in all regions except in the boreal needleleaved forests where the woody litter stocks are at the high end. At the northern boundary of boreal forests, the model

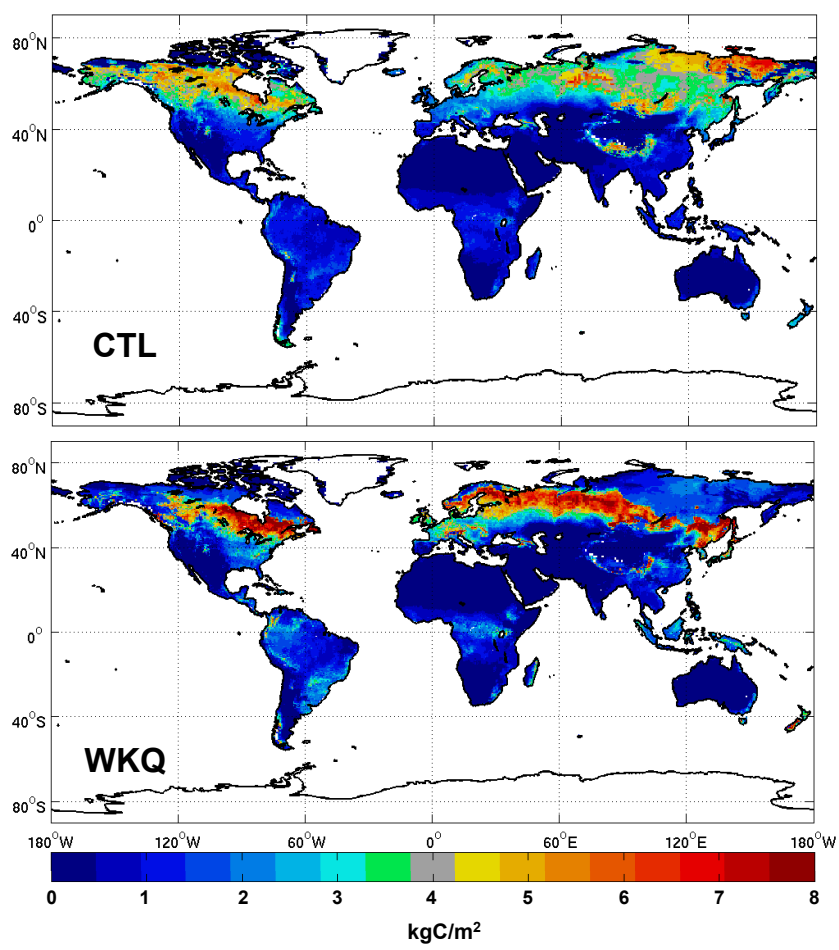

Fig. 4. Distribution of total litter stocks $\left(\mathrm{kg} \mathrm{Cm}^{-2}\right)$ in the CTL (top) and WKQ (bottom) simulations. See Table 4 and Sect. 2.3 for the simulation setup. Effects of anthropogenic changes in land cover on vegetation distribution and carbon stocks were not accounted for. 


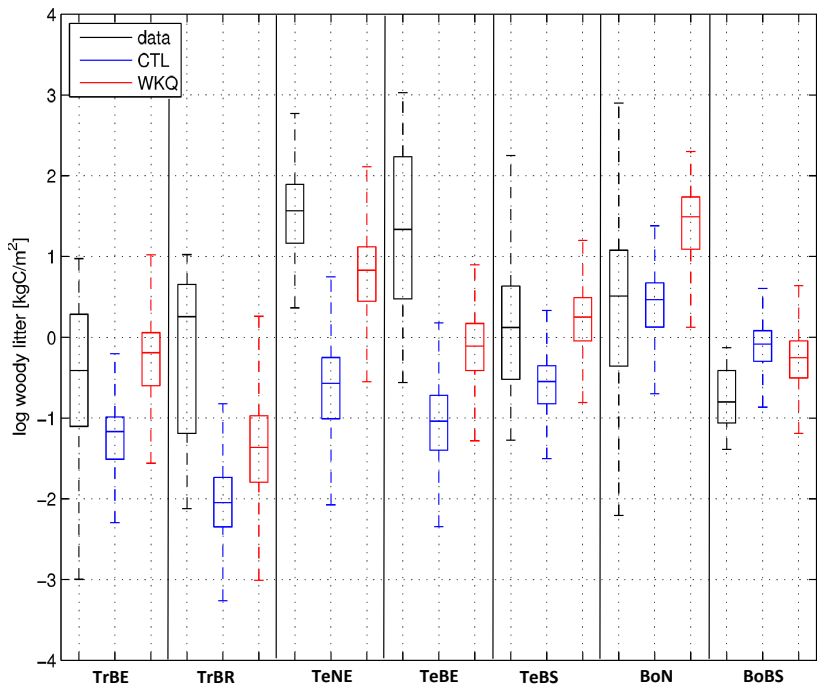

Fig. 5. Woody litter stocks $\left(\mathrm{kg} \mathrm{C} \mathrm{m}^{-2}\right.$, natural logarithm scale) simulated in the CTL and WKQ simulations compared to the Functional Ecology of Trees (FET) trait database aggregated to 7 woody Plant functional types (PFTs), see Table 1 for the PFT acronyms, Table 2 for statistical analysis, and Table 4 for the simulation setup. For representing the model outputs, only grid cells where the simulated fractional projection cover of the PFT in question was higher than $50 \%$ were taken into account to allow adequate comparison with the observations. In the CTL experiment, woody and leaf litter stocks were calculated separately for comparison.

overestimates the living biomass stocks by a factor of two, in particular because of the absence of a permafrost parameterization which otherwise would limit tree growth substantially, and this is reflected in the high litter stocks (overestimated by ca. $80 \%$, see Table 2). This calls for improvement in modelling the biomass distribution in high northern latitudes, as discussed above. Despite this bias, the new parameterization of the litter decomposition leads to a much improved worldwide distribution of litter stocks. The statistical analysis of woody litter data reveals a significant underestimation of litter stocks in all regions in the CTL simulation while the data and model results of the WKQ simulation are in much closer agreement (Table 2). The ANOVA $F$ value is less for the WKQ simulation than for the CTL simulation for all PFTs, including boreal needleleaved trees. The global flux of leaf litter in the WKQ simulation $\left(19.9 \mathrm{Gt} \mathrm{C} \mathrm{yr}^{-1}\right)$ is almost double the woody litter flux $\left(11.0 \mathrm{Gt} \mathrm{C} \mathrm{yr}^{-1}\right)$. Despite the smaller input flux, the woody litter dominates in total litter stocks (ca. $75 \%$ ) because its decomposition rate is slower by an order of magnitude than the decomposition rate of the leaf litter (Table 1).

Results from the W simulation suggest that the main improvement in the global distribution of litter is due to separation of litter into leaf and woody components (Fig. 6). The bias in the polar tundra region is partly removed. The $\mathrm{W}$ simulation uses $k-$ values averaged from the trait databases $(0.94$

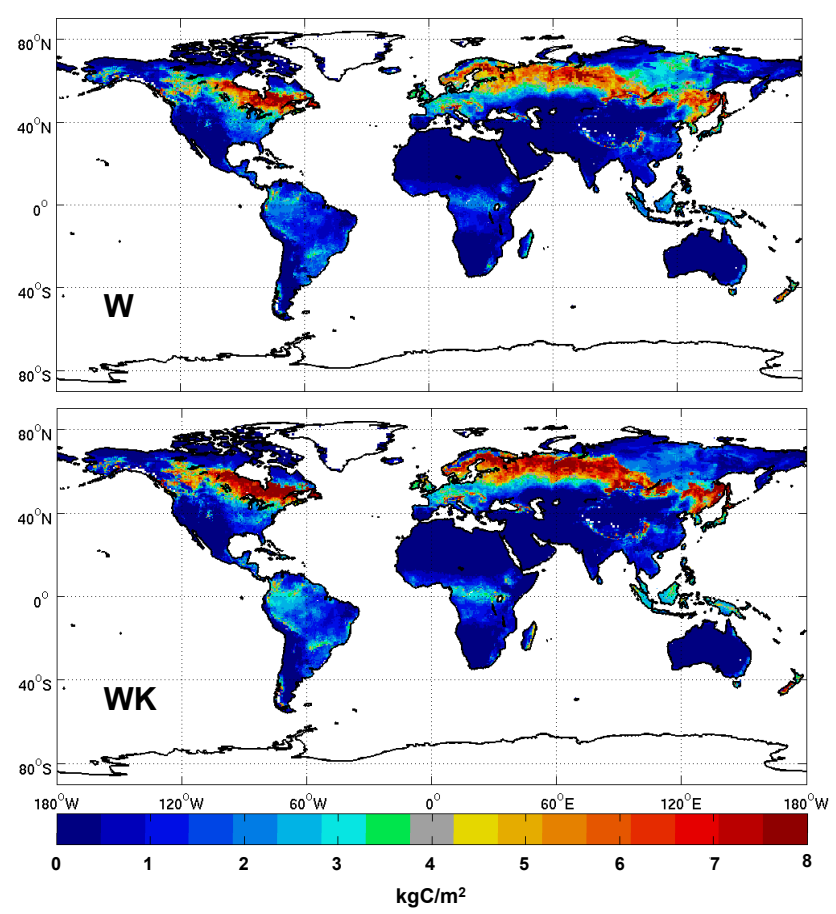

Fig. 6. Distribution of total litter stocks $\left(\mathrm{kg} \mathrm{C} \mathrm{m}^{-2}\right)$ in the $\mathrm{W}$ (top) and WK (bottom) simulations. See Table 4 and text for the simulation setup. Effects of anthropogenic changes in land cover on vegetation distribution and carbon stocks were not accounted for.

and $0.057 \mathrm{yr}^{-1}$ for the leaf and woody litter at $10^{\circ} \mathrm{C}$, respectively). Accounting for the PFT-dependent decomposition constants in the WK simulation completely removes the litter stock bias in north-eastern Siberia, and the PFT-dependent $Q_{10}$ values in the WKQ simulation decreases litter stocks in tropical regions towards more realistic values, where the relatively higher sensitivity to temperature $\left(Q_{10}=2.75\right.$, Table 1) partly reflects the greater contribution of xylophageous insects, especially termites, to wood turnover in warmer biomes (Cornwell et al., 2009) (see Sect. 2.2 and Fig. 3 for more details on the procedure for constraining $Q_{10}$ ). The W, $\mathrm{WK}$, and WKQ simulations excluded the modulation by soil moisture on litter decomposition (Foley, 1995; Sitch et al., 2003). Higher moisture can promote the decomposition of soil organic matter and leaf litter, but for woody litter the contact with soil moisture is much less and excess moisture may even reduce decomposition, especially in the tropics (Torres and Gonzalez, 2005).

Using the ART-DECO (Cornwell et al., 2008) and FET databases (Weedon et al., 2009), we assigned $\mathrm{N}$ and $\mathrm{P}$ contents to the leaf and woody litter of each PFT (Table 3). In the CTL simulation, the global litter stock holds 2.7 and $0.17 \mathrm{Pg}$ of $\mathrm{N}$ and P, respectively. Despite higher litter stocks, the WKQ simulation keeps much less nutrients in litter pools (1.5 PgN and $0.09 \mathrm{PgP}$ ), because the bulk of the stock consists of nutrient-poor woody litter. Smaller nutrient litter 
Table 3. $\mathrm{N}$ and $\mathrm{P}$ content of litter used to diagnose leaf litter nutrient stocks following ART-DECO dataset (Cornwell et al., 2008).

\begin{tabular}{lrr}
\hline LPJ Plant Functional Type & C:N $(\mathrm{g}: \mathrm{g})$ & $\mathrm{C}: \mathrm{P}(\mathrm{g}: \mathrm{g})$ \\
\hline tropical broadleaved evergreen tree & 55.9 & 1665 \\
tropical broadleaved raingreen tree & 29.4 & 781 \\
temperate needleleaved evergreen tree & 63.8 & 1075 \\
temperate broadleaved evergreen tree & 72.8 & 1721 \\
temperate broadleaved summergreen tree & 46.4 & 627 \\
boreal needleleaved tree & 68.4 & 940 \\
boreal broadleaved summergreen tree & 65.5 & 1055 \\
$\mathrm{C}_{3}$ perennial grass & 47.6 & 657 \\
$\mathrm{C}_{4}$ perennial grass & 54.1 & 1956 \\
\hline
\end{tabular}

For woody litter, C:N and C:P ratios were taken as 156 and 2340 for broadleaved, and as 454 and 6474 for needleaved trees, respectively, based on results by Weedon et al. (2009).

content could reduce nutrient supply during the growing season and may lead to a progressive nutrient limitation under elevated $\mathrm{CO}_{2}$ concentrations (Luo et al., 2004), stressing the importance of further analysis using a model that includes interactive $\mathrm{N}$ and $\mathrm{P}$ cycles.

To test the consequences of this improved litter parameterization for atmospheric $\mathrm{CO}_{2}$ concentration and climate in the future, we used an Earth System model of intermediate complexity, CLIMBER2-LPJ (Kleinen et al., 2010), in simulations with a representative climate scenario, SRES A2 (see Methods). In response to fossil fuel emissions and climate change, the atmospheric $\mathrm{CO}_{2}$ concentration increases during the entire 21 st century by $380 \mathrm{ppm}$ and $377 \mathrm{ppm}$ in the CTL$\mathrm{T}$ and WKQ-T simulations ( $\mathrm{T}$ for transient), respectively (Table 5). Lower $\mathrm{CO}_{2}$ concentration in the WKQ-T experiment is explained by a $31 \mathrm{GtC}$ higher total litter stock accumulation counteracted by a decrease of $24 \mathrm{Gt} C$ in biomass stocks. While the global increase of litter stocks at the end of the 21 st century is rather similar for both experiments, the geographical patterns of these changes are different. The CTL-T simulation results in a rather homogeneous increase in litter stocks in the tropics and subtropics and elevated litter aggregation in the polar region. The WKQ parameterization predominantly leads to greater carbon storage at the southern boundary of boreal forests. Both CTL-T and WKQ-T simulations show a strong increase by $50 \%$ in wildfire emissions during the 21 st century (Table 5). The fire-prone area increases mostly in subtropical dryland areas following elevated litter stocks due to a $\mathrm{CO}_{2}$ fertilization effect and woody encroachment. Despite a relatively stronger increase in litter stocks, the WKQ-T simulation has slightly lower wildfire carbon emissions (Table 5), because of litter redistribution towards more humid regions. While litter storage is an important parameter which can limit or promote a fire by controlling fire spread rates (Thonicke et al., 2010; Rothermel, 1972), other factors, such as humidity, contribute to the complex fire behaviour as well.

\section{Discussion and conclusions}

Earth System Models are extremely simple in representing plant functional diversity in general, but particularly when it concerns plant effects on its environment. In most, if not all, models variation in responses of plant traits and their afterlife effects on litter quality are neglected. Our study thus represents one of the first attempts to incorporate variation in these trait responses. We acknowledge that many improvements can still be made, but it is also important to acknowledge the principal step forward taken by our approach given the biological simplicity of current generation of Earth System models.

The litter decomposition rates vary within PFTs. As far as that variation is due to prevailing environmental conditions, our model accounts for it, thus capturing a major fraction of the variability in decomposition within PFTs. We cannot account for differences in litter quality within PFTs in a given environment because ESMs do not calculate the necessary traits that are known to determine $k_{\text {leaf }}$ or $k_{\text {wood }}$ values. Only recently did ESMs start to simulate leaf nitrogen contents, an important driver of $k_{\text {leaf }}$, but no ESM accounts for lignins, phenolics, tannins or any other key chemical determinant of litter quality, let alone allowing these characteristics to vary within PFTs. However, given that we estimated $k_{\text {leaf }}$ values based on global relations between $k_{\text {leaf }}$ and litter $\mathrm{N}$ and lignin (explaining a large percentage of the variation in $k_{\text {leaf }}$; see Fig. 1), our approach can easily be extended to include the variation in $k_{\text {leaf }}$ within PFTs as soon as estimates on global variations in litter traits become available.

The data that we used to derive the $k_{\text {leaf }}$ values reported in Table 1 currently represent the largest global databases in their kind, derived from studies that measured leaf litter $k_{\text {leaf }}$. Extracting generic and representative PFT-specific parameter values from a heterogeneous dataset of world-wide observations required a sophisticated pre-processing. In order to extract PFT-specific estimates of baseline decomposition rates and temperature sensitivities, a wide range of chemical, structural and environmental variables had to be controlled 
Table 4. Setup of numerical experiments.

\begin{tabular}{|c|c|c|c|}
\hline $\begin{array}{l}\text { Simulation } \\
\text { acronym }\end{array}$ & $\begin{array}{c}\text { Separate } k_{\text {leaf } 10} \\
\text { and } k_{\text {wood } 10} \text { values }\end{array}$ & $\begin{array}{l}\text { PFT-specific } k_{\text {leaf } 10} \\
\text { and } k_{\text {wood } 10}\end{array}$ & $\begin{array}{l}\text { PFT-specific } Q_{10} \text {-values } \\
\text { for } k_{\text {wood }}\end{array}$ \\
\hline \multicolumn{4}{|c|}{ Equilibrium simulations (1000 yr with pre-industrial $\mathrm{CO}_{2}$ level of $280 \mathrm{ppm}$ ) } \\
\hline $\mathrm{CTL}^{*}$ & No & No & No \\
\hline $\mathrm{W}^{* *}$ & Yes & No & No \\
\hline WK & Yes & Yes & No \\
\hline WKQ & Yes & Yes & Yes \\
\hline \multicolumn{4}{|c|}{ Transient simulations (historical $\mathrm{CO}_{2}$ emissions + SRES A2 scenario, years 1750-2100) } \\
\hline CTL-T & No & No & No \\
\hline CTL-WKQ & Yes & Yes & Yes \\
\hline
\end{tabular}

${ }^{*} k_{\text {leaf } 10}=k_{\mathrm{wood} 10}=0.3 \mathrm{yr}^{-1} . * *$ Averaged trait-dataset values, $k_{\text {leaf } 10}=0.94 \mathrm{yr}^{-1}$ and $k_{\mathrm{wood} 10}=0.057 \mathrm{yr}^{-1}$.

Table 5. Results of transient CLIMBER-LPJ simulations.

\begin{tabular}{|c|c|c|c|c|c|c|}
\hline \multirow[t]{2}{*}{ Years/Variable } & \multicolumn{2}{|c|}{ 1891-1900* } & \multicolumn{2}{|c|}{ 1991-2000 } & \multicolumn{2}{|c|}{$2091-2100$} \\
\hline & CTL-T & WKQ-T & CTL-T & WKQ-T & CTL-T & WKQ-T \\
\hline Atmospheric $\mathrm{CO}_{2}$ concentration, ppm & 287 & 287 & 345 & 344 & 725 & 722 \\
\hline Litter stocks, Gt C & 184 & 191 & 191 & 196 & 242 & 277 \\
\hline Biomass, Gt C & 597 & 597 & 709 & 716 & 1112 & 1095 \\
\hline Soil carbon, Gt C & 1349 & 1368 & 1356 & 1374 & 1452 & 1469 \\
\hline Wildfire emissions, ${\mathrm{Gt} \mathrm{C} \mathrm{yr}^{-1}}^{-1}$ & 3.1 & 2.9 & 3.6 & 3.3 & 5.3 & 5.0 \\
\hline
\end{tabular}

* Decadal averaged values.

for (Kattge et al., 2011b). The value of the databases at hand is specifically due to the availability of such covariates. In the case of leaf litter, $k_{\text {leaf }}$-values were linked to litter chemistry to predict the variation in $k_{\text {leaf }}$ within and between PFTs. Subsequently, we predicted $k$ from the average litter lignin and litter N contents of that PFT. For woody litter, we accounted for log dimensions, degree of soil contact, and precipitation in order to improve our estimates of baseline rates and temperature sensitivities. This led to highly robust estimates of $k$ (see Figs. 1 and 2 for illustration of variation in $k_{\text {leaf }}$ and $k_{\text {wood }}$, respectively).

While we included the effects of temperature, precipitation and litter quality, there are other factors affecting decomposition such as soil decomposers. Soil decomposers have been included implicitly, however, because decomposition experiments were run at local conditions with local soil fauna, albeit that macro-detritivores had been excluded due to the use of litter bags (but including meso- and micro-detritivores). In those cases where soil macro-detritivores do account for substantial additional variation in decomposition rates, notably in the tropics (see tropical forest studies by Hattenschwiler and Jorgensen, 2010), they must be part of the $25 \%$ residual variance in the $k$-values. Our two litter chemical and environmental parameters explained the other $75 \%$ of variation in decomposition rates. We therefore assume that soil decomposers are less important than these parameters, which is confirmed by global studies (Aerts, 1997; Berg et al., 1993; Meentemeyer, 1978; Cornelissen et al., 2007 for a cold-biome example). Even if we had included additional $k$ variance due to soil decomposers in our decomposition studies, we still would not have been able to account for them in our numerical experiments given that ESMs do not model soil decomposers. In the case of wood decomposition rates, the strong increase in decomposition rates with temperature is almost certainly due to the fact that wood-degrading termite activity commences beyond a certain threshold of meanannual temperature (Cornwell et al., 2009). The effects of temperature and precipitation incorporated in our model have been derived from global relations between environmental conditions and decomposability and are generally accepted.

Plant litter dynamics are essential for the land-atmosphere carbon flux because this organic carbon stock is easily available for microbial decomposition and for abrupt release to the atmosphere through wildfires. Despite a large amount of local data on litter stocks across the globe, a synthesis of the global litter distribution is not readily available. Uncertainty in global litter storage remains high (Denman et al., 2007; Matthews, 1997), in particular because woody litter 
storages are difficult to quantify on a global scale. It is therefore inevitable that, for some time, carbon cycle models will be utilized as the best available source of information on the spatial distribution of litter stocks used for carbon cycle projections. Using most recently compiled datasets on species trait effects on litter decomposition (Cornwell et al., 2008; Weedon et al., 2009), we remarkably improved the modelled distribution of litter stocks (Fig. 4), although model results are still far from perfect when compared to local data. We have not addressed here an effect of uncertainty in decomposition rates on uncertainty estimates of global litter stocks and projected atmospheric $\mathrm{CO}_{2}$ concentration. A detailed uncertainty analysis goes beyond an illustrative purpose of this study.

Re-parameterisation of models based on trait datasets is not entirely free from biases. Woody litter estimates, for example, are often done for mature forests and this can partly explain the disagreement between the data and global models such as LPJ which simulate averaged forest stands without accounting for the tree age structure. Removing this kind of structural bias is an essential part of model improvement. Altogether, incorporating trait-based relationships into Earth System models constitutes a major step forward for better forecasting land ecosystem process rates including carbon and nutrient cycling, and fire regimes.

Acknowledgements. The authors acknowledge the original contributors of the invaluable plant trait and decomposition data underlying the ART-DECO and FET databases as well as support for working groups 4, 17 and 35 by the Australian Research Council through the ARC - New Zealand Research Network for Vegetation Function; and Mark Westoby and Ian Wright for coordinating these working group workshops. The authors are also grateful to the COST Action ES0805 TERRABITES for providing support for extensive discussions of trait database applications for the global-scale modelling. The authors thank two anonymous reviewers for their constructive and helpful comments.

The service charges for this open access publication have been covered by the Max Planck Society.

Edited by: M. Bahn

\section{References}

Aerts, R.: Nitrogen partitioning between resorption and decomposition pathways: a trade-off between nitrogen use efficiency and litter decomposibility?, Oikos, 80, 603-606, 1997.

Allen, S. E.: Chemical analysis of ecological materials, Blackwell Scientific Publications, Oxford, 368 pp., 1989.

Bazilevich, N. I.: Biological productivity of ecosystems of Northern Eurasia Nauka, Moscow, 293 pp., 1993.

Berg, B., Berg, M. P., Bottner, P., Box, E., Breymeyer, A., Deanta, R. C., Couteaux, M., Escudero, A., Gallardo, A., Kratz, W., Madeira, M., Malkonen, E., McClaugherty, C., Meentemeyer, V., Munoz, F., Piussi, P., Remacle, J., and Desanto, A. V.: Litter mass-loss rates in pine forests of Europe and eastern United-
States - some relationships with climate and litter quality, Biogeochemistry, 20, 127-159, 1993.

Boden, T. A., Marland, G., and Andres, R. J.: Global, Regional, and National Fossil-Fuel $\mathrm{CO}_{2}$ Emissions, Carbon Dioxide Information Analysis Center, Oak Ridge National Laboratory, U.S. Department of Energy, Oak Ridge, Tenn., USA, 2010.

Brovkin, V., Bendtsen, J., Claussen, M., Ganopolski, A., Kubatzki, C., Petoukhov, V., and Andreev, A.: Carbon cycle, vegetation, and climate dynamics in the Holocene: Experiments with the CLIMBER-2 model, Global Biogeochem. Cy., 16, 1139, doi:10.1029/2001gb001662, 2002.

Churkina, G., Brovkin, V., von Bloh, W., Trusilova, K., Jung, M., and Dentener, F.: Synergy of rising nitrogen depositions and atmospheric $\mathrm{CO}_{2}$ on land carbon uptake moderately offsets global warming, Global Biogeochem. Cy., 23, Gb4027, doi:10.1029/2008gb003291, 2009.

Cornelissen, J. H. C., van Bodegom, P. M., Aerts, R., Callaghan, T. V., van Logtestijn, R. S. P., Alatalo, J., Chapin, F. S., Gerdol, R., Gudmundsson, J., Gwynn-Jones, D., Hartley, A. E., Hik, D. S., Hofgaard, A., Jonsdottir, I. S., Karlsson, S., Klein, J. A., Laundre, J., Magnusson, B., Michelsen, A., Molau, U., Onipchenko, V. G., Quested, H. M., Sandvik, S. M., Schmidt, I. K., Shaver, G. R., Solheim, B., Soudzilovskaia, N. A., Stenstrom, A., Tolvanen, A., Totland, O., Wada, N., Welker, J. M., and Zhao, X. Q.: Global negative vegetation feedback to climate warming responses of leaf litter decomposition rates in cold biomes, Ecol. Lett., 10, 619-627, doi:10.1111/j.1461-0248.2007.01051.x, 2007.

Cornwell, W. K., Cornelissen, J. H. C., Amatangelo, K., Dorrepaal, E., Eviner, V. T., Godoy, O., Hobbie, S. E., Hoorens, B. Kurokawa, H., Perez-Harguindeguy, N., Quested, H. M., Santiago, L. S., Wardle, D. A., Wright, I. J., Aerts, R., Allison, S. D., van Bodegom, P., Brovkin, V., Chatain, A., Callaghan, T. V., Diaz, S., Garnier, E., Gurvich, D. E., Kazakou, E., Klein, J. A., Read, J., Reich, P. B., Soudzilovskaia, N. A., Vaieretti, M. V., and Westoby, M.: Plant species traits are the predominant control on litter decomposition rates within biomes worldwide, Ecol. Lett, 11, 1065-1071, doi:10.1111/j.1461-0248.2008.01219.x, 2008.

Cornwell, W. K., Cornelissen, J. H. C., Allison, S. D., Bauhus, J., Eggleton, P., Preston, C. M., Scarff, F., Weedon, J. T., Wirth, C., and Zanne, A. E.: Plant traits and wood fates across the globe: rotted, burned, or consumed?, Glob. Change Biol., 15, 24312449, doi:10.1111/j.1365-2486.2009.01916.x, 2009.

Cramer, W., Bondeau, A., Woodward, F. I., Prentice, I. C., Betts, R. A., Brovkin, V., Cox, P. M., Fisher, V., Foley, J. A., Friend, A. D., Kucharik, C., Lomas, M. R., Ramankutty, N., Sitch, S., Smith, B., White, A., and Young-Molling, C.: Global response of terrestrial ecosystem structure and function to $\mathrm{CO}_{2}$ and climate change: results from six dynamic global vegetation models, Glob. Change Biol., 7, 357-373, 2001.

Denman, K. L., Brasseur, G., Chidthaisong, A., Ciais, P., Cox, P. M., Dickinson, R. E., Hauglustaine, D., Heinze, C., Holland, E., Jacob, D., Lohmann, U., Ramachandran, S., Silva Dias, P. L., Wofsy, S. C., and Zhang, X.: Couplings Between Changes in the Climate System and Biogeochemistry, in: The Physical Science Basis. Contribution of Working Group I to the Fourth Assessment Report of the Intergovernmental Panel on Climate Change, edited by: Solomon, S., Qin, D., Manning, M., Chen, Z., Marquis, M., Averyt, K. B., Tignor, M., and Miller, H. L., Cambridge University Press, Cambridge, 501-587, 2007. 
Foley, J. A.: An equilibrium-model of the terrestrial carbon budget, Tellus Series B-Chem. Phys. Meteorol., 47, 310-319, 1995.

Friedlingstein, P., Cox, P., Betts, R., Bopp, L., Von Bloh, W., Brovkin, V., Cadule, P., Doney, S., Eby, M., Fung, I., Bala, G., John, J., Jones, C., Joos, F., Kato, T., Kawamiya, M., Knorr, W., Lindsay, K., Matthews, H. D., Raddatz, T., Rayner, P., Reick, C., Roeckner, E., Schnitzler, K. G., Schnur, R., Strassmann, K., Weaver, A. J., Yoshikawa, C., and Zeng, N.: Climate-carbon cycle feedback analysis: Results from the (CMIP)-M-4 model intercomparison, J. Climate, 19, 3337-3353, 2006.

Gerber, S., Hedin, L. O., Oppenheimer, M., Pacala, S. W., and Shevliakova, E.: Nitrogen cycling and feedbacks in a global dynamic land model, Global Biogeochem. Cy., 24, Gb1001, doi:10.1029/2008gb003336, 2010.

Gerten, D., Schaphoff, S., Haberlandt, U., Lucht, W., and Sitch, S.: Terrestrial vegetation and water balance - hydrological evaluation of a dynamic global vegetation model, J. Hydrol., 286, 249-270, doi:10.1016/j.jhydrol.2003.09.029, 2004.

Hattenschwiler, S. and Jorgensen, H. B.: Carbon quality rather than stoichiometry controls litter decomposition in a tropical rain forest, J. Ecol., 98, 754-763, doi:10.1111/j.13652745.2010.01671.x, 2010.

Kattge, J., Knorr, W., Raddatz, T., and Wirth, C.: Quantifying photosynthetic capacity and its relationship to leaf nitrogen content for global-scale terrestrial biosphere models, Glob. Change Biol., 15, 976-991, doi:10.1111/j.1365-2486.2008.01744.x, 2009.

Kattge, J., Díaz, S., Lavorel, S., Prentice, I. C., Leadley, P., Bönisch, G., Garnier, E., Westoby, M., Reich, P. B., Wright, I. J., Cornelissen, J. H. C., Violle, C., Harrison, S. P., van Bodegom, P. M., Reichstein, M., Enquist, B. J., Soudzilovskaia, N. A., Ackerly, D. D., Anand, M., Atkin, O., Bahn, M., Baker, T. R., Baldocchi, D., Bekker, R., Blanco, C. C., Blonder, B., Bond, W. J., Bradstock, R., Bunker, D. E., Casanoves, F., Cavender-Bares, J., Chambers, J. Q., Chapin III, F. S., Chave, J., Coomes, D., Cornwell, W. K., Craine, J. M., Dobrin, B. H., Duarte, L., Durka, W., Elser, J., Esser, G., Estiarte, M., Fagan, W. F., Fang, J., FernándezMéndez, F., Fidelis, A., Finegan, B., Flores, O., Ford, H., Frank, D., Freschet, G. T., Fyllas, N. M., Gallagher, R. V., Green, W. A., Gutierrez, A. G., Hickler, T., Higgins, S. I., Hodgson, J. G., Jalili, A., Jansen, S., Joly, C. A., Kerkhoff, A. J., Kirkup, D., Kitajima, K., Kleyer, M., Klotz, S., Knops, J. M. H., Kramer, K., Kühn, I., Kurokawa, H., Laughlin, D., Lee, T. D., Leishman, M., Lens, F., Lenz, T., Lewis, S. L., Lloyd, J., Llusià, J., Louault, F., Ma, S., Mahecha, M. D., Manning, P., Massad, T., Medlyn, B. E., Messier, J., Moles, A. T., Müller, S. C., Nadrowski, K., Naeem, S., Niinemets, Ü., Nöllert, S., Nüske, A., Ogaya, R., Oleksyn, J., Onipchenko, V. G., Onoda, Y., Ordoñez, J., Overbeck, G., Ozinga, W. A., Patiño, S., Paula, S., Pausas, J. G., Peñuelas, J., Phillips, O. L., Pillar, V., Poorter, H., Poorter, L., Poschlod, P., Prinzing, A., Proulx, R., Rammig, A., Reinsch, S., Reu, B., Sack, L., Salgado-Negret, B., Sardans, J., Shiodera, S., Shipley, B., Siefert, A., Sosinski, E., Soussana, J.-F., Swaine, E., Swenson, N., Thompson, K., Thornton, P., Waldram, M., Weiher, E., White, M., White, S., Wright, S. J., Yguel, B., Zaehle, S., Zanne, A. E., and Wirth, C.: TRY - a global database of plant functional traits, Glob. Change Biol., 17, 2905-2935, doi:10.1111/j.13652486.2011.02451.x, 2011a.

Kattge, J., Ogle, K., Bonisch, G., Diaz, S., Lavorel, S., Madin, J., Nadrowski, K., Nollert, S., Sartor, K., and Wirth, C.: A generic structure for plant trait databases, Methods Ecol. Evol., 2, 202213, doi:10.1111/j.2041-210X.2010.00067.x, 2011b.

Kleinen, T., Brovkin, V., von Bloh, W., Archer, D., and Munhoven, G.: Holocene carbon cycle dynamics, Geophys. Res. Lett., 37, L02705, doi:10.1029/2009GL041391, 2010.

Lloyd, J. and Taylor, J. A.: On the temperature-dependence of soil respiration, Funct. Ecol., 8, 315-323, 1994.

Lunn, D. J., Thomas, A., Best, N., and Spiegelhalter, D.: WinBUGS - a Bayesian modelling framework: concepts, structure, and extensibility, Stat. Comput., 10, 325-337, 2000.

Luo, Y., Su, B., Currie, W., Dukes, J., Finzi, A., Hartwig, U., Hungate, B., McMurtrie, R. E., Oren, R., Parton, W. J., Pataki, D. E., Shaw, M. R., Zak, D. R., and Field, C. B.: Progressive nitrogen limitation of ecosystem responses to rising atmospheric carbon dioxide, Bioscience, 54, 731-739, 2004.

Matthews, E.: Global litter production, pools, and turnover times: Estimates from measurement data and regression models, J. Geophys. Res.-Atmos., 102, 18771-18800, 1997.

Meentemeyer, V.: Macroclimate and lignin control of litter decomposition rates, Ecology, 59, 465-472, 1978.

New, M., Hulme, M., and Jones, P.: Representing twentieth-century space-time climate variability, Part I: Development of a 1961-90 mean monthly terrestrial climatology, J. Climate, 12, 829-856, 1999.

New, M., Lister, D., Hulme, M., and Makin, I.: A high-resolution data set of surface climate over global land areas, Clim. Res., 21, 1-25, 2002.

Parton, W. J., Scurlock, J. M. O., Ojima, D. S., Gilmanov, T. G., Scholes, R. J., Schimel, D. S., Kirchner, T., Menaut, J. C., Seastedt, T., Moya, E. G., Kamnalrut, A., and Kinyamario, J. I.: Observations and modeling of biomass and soil organic-matter dynamics for the grassland biome worldwide, Global Biogeochem. Cy., 7, 785-809, 1993.

Parton, W. J., Silver, W. L., Burke, I. C., Grassens, L., Harmon, M. E., Currie, W. S., King, J. Y., Adair, E. C., Brandt, L. A., Hart, S. C., and Fasth, B.: Global-scale similarities in nitrogen release patterns during long-term decomposition, Science, 315, 361-364, doi:10.1126/science.1134853, 2007.

Petoukhov, V., Ganopolski, A., Brovkin, V., Claussen, M., Eliseev, A., Kubatzki, C., and Rahmstorf, S.: CLIMBER-2: a climate system model of intermediate complexity, Part I: model description and performance for present climate, Clim. Dynam., 16, 1$17,2000$.

Rothermel, R. C.: A Mathematical Model for Predicting Fire Spread in Wildland Fuels, Intermountain Forest and Range Experiment Station, Forest Service, US Dept. of Agriculture, Ogden, 1972.

Sitch, S., Smith, B., Prentice, I. C., Arneth, A., Bondeau, A., Cramer, W., Kaplan, J. O., Levis, S., Lucht, W., Sykes, M. T., Thonicke, K., and Venevsky, S.: Evaluation of ecosystem dynamics, plant geography and terrestrial carbon cycling in the LPJ dynamic global vegetation model, Glob. Change Biol., 9, 161185, 2003.

Sokolov, A. P., Kicklighter, D. W., Melillo, J. M., Felzer, B. S., Schlosser, C. A., and Cronin, T. W.: Consequences of considering carbon-nitrogen interactions on the feedbacks between climate and the terrestrial carbon cycle, J. Climate, 21, 3776-3796, doi:10.1175/2008jcli2038.1, 2008.

Thonicke, K., Spessa, A., Prentice, I. C., Harrison, S. P., Dong, 
L., and Carmona-Moreno, C.: The influence of vegetation, fire spread and fire behaviour on biomass burning and trace gas emissions: results from a process-based model, Biogeosciences, 7, 1991-2011, doi:10.5194/bg-7-1991-2010, 2010.

Thornton, P. E., Lamarque, J. F., Rosenbloom, N. A., and Mahowald, N. M.: Influence of carbon-nitrogen cycle coupling on land model response to $\mathrm{CO}_{2}$ fertilization and climate variability, Global Biogeochem. Cy., 21, Gb4018, doi:10.1029/2006gb002868, 2007.

Torres, J. A. and Gonzalez, G.: Wood decomposition of Cyrilla racemiflora (Cyrillaceae) in Puerto Rican dry and wet forests: A 13-year case study, Biotropica, 37, 452-456, doi:10.1111/j.17447429.2005.00059.x, 2005.

Usher, M. B. and Ocloo, J. K.: The Natural Resistance of 85 West African Hardwood Timbers to Attack by Termites and Microorganisms, Tropical Pest Bulletin, 6, 1-47, 1979.

Wang, Y. P., Law, R. M., and Pak, B.: A global model of carbon, nitrogen and phosphorus cycles for the terrestrial biosphere, Biogeosciences, 7, 2261-2282, doi:10.5194/bg-7-2261-2010, 2010.
Weedon, J. T., Cornwell, W. K., Cornelissen, J. H. C., Zanne, A. E., Wirth, C., and Coomes, D. A.: Global meta-analysis of wood decomposition rates: a role for trait variation among tree species?, Ecol. Lett., 12, 45-56, doi:10.1111/j.1461-0248.2008.01259.x, 2009.

Wright, I. J., Reich, P. B., Westoby, M., Ackerly, D. D., Baruch, Z., Bongers, F., Cavender-Bares, J., Chapin, T., Cornelissen, J. H. C., Diemer, M., Flexas, J., Garnier, E., Groom, P. K., Gulias, J., Hikosaka, K., Lamont, B. B., Lee, T., Lee, W., Lusk, C., Midgley, J. J., Navas, M. L., Niinemets, U., Oleksyn, J., Osada, N., Poorter, H., Poot, P., Prior, L., Pyankov, V. I., Roumet, C., Thomas, S. C., Tjoelker, M. G., Veneklaas, E. J., and Villar, R.: The worldwide leaf economics spectrum, Nature, 428, 821-827, doi:10.1038/nature02403, 2004.

Zaehle, S., Friedlingstein, P., and Friend, A. D.: Terrestrial nitrogen feedbacks may accelerate future climate change, Geophys. Res. Lett., 37, L01401, doi:10.1029/2009g1041345, 2010. 